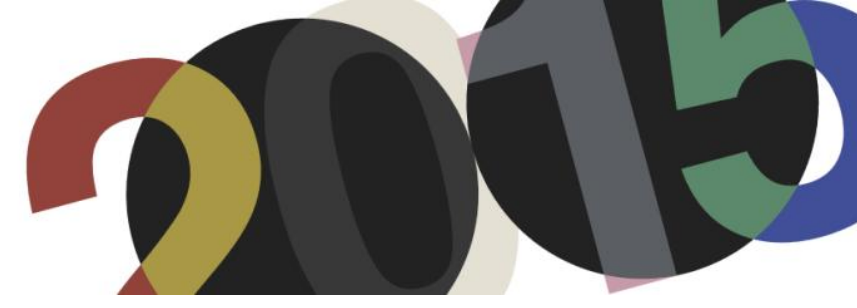

DOI: http://dx.doi.org/10.4995/LC2015.2015.567

\title{
Le Corbusier y el edificio del Ministerio de Educación y Salud
}

\author{
L. Scottá
}

Faculdade de Arquitectura da Universidade do Porto

\begin{abstract}
Resumen: Este artículo presenta una reflexión acerca del edificio del Ministerio de Educación y Salud, en Rio de Janeiro/ Brasil - un proyecto de varios arquitectos brasileños con la colaboración de Le Corbusier. El objetivo es analizar el procesos de la obra a partir de la comparación de tres publicaciones: Cuvre Complete 1934-1938, Brazil Builds: Architecture New and Old: 1652-1942 y Euvre Complete 1938-1946. Con el análisis de estos tres libros se presenta una visión completa desde el proceso de diseño hasta el final de la construcción. Es decir, puede ser vista la creación de un edificio. Mientras que el primer libro muestra un proyecto incipiente, en la etapa de progreso de ideas y propuestas, el segundo - Brazil Builds - presenta la construcción en proceso. Finalmente, el último libro muestra el diseño final y las fotografías del edificio ya construido, sólo un año después de su finalización
\end{abstract}

Abstract: This paper discusses the Ministry of Education \& Health building in Rio de Janeiro/Brazil - a project developed by several Brazilian architects in collaboration with Le Corbusier. The aim is to analyze the working process by comparing three publications: Euvre Complete 1934-1938, Brazil Builds: Architecture New and Old: 1652-1942 and Euvre Complete 1938-1946. The analysis of these three books presents a complete outlook of the building's design, from its beginning up to its construction. In other words, one can see the creation of a building. While the first book introduces the project in an incipient stage, going through the progress of elaborating ideas and proposals, the second - Brazil Builds - presents the construction process of the building. Finally, the last book presents the final design and photographs of the building already built, just a year after being finished.

Palabras clave: Brazil Builds; Le Corbusier; Arquitectura moderna brasileña. Keywords: Brazil Builds; Le Corbusier, Brazilian Modern Architecture.

\section{El proyecto del Ministerio de Educación y Salud}

La primera mitad del siglo XX condujo a Brasil a un gran progreso en varias áreas. Fue una época de crecimiento y evolución. Como afirma Williams: "A mediados del siglo XX, Brasil fue un ejemplo de desarrollo moderno. Durante este período no es exagerado decir que Brasil fue el país más moderno del mundo"1. El Ministerio de Educación y Salud (MES), diseñado en 1936, se convirtió en el emblema² del proceso de desarrollo del modernismo en la arquitectura brasileña. En abril de 1935, se convocó un concurso de proyectos para la construcción de la sede del Ministerio. Las normas del plan urbano de Río de Janeiro, que deberían ser respetadas, recomendaban: "retranqueo homogéneo de la edificación en relación a los límites del terreno (alineación), la construcción de edificios como bloques con zonas internas para ventilación e iluminación, además de entradas por las cuatro caras ${ }^{\prime \prime 3}$. El jurado eliminó fulminantemente los proyectos que contravinieron las reglas, quedando tres proyectos que tendrían un período adicional para su desarrollo hasta la decisión final. El

\footnotetext{
${ }^{1}$ WILLIANS, Richard: Brazil - Modern Architectures in history. Londres: Reaktion Books Ld, 2009. p.7. (Traducción del autor)

${ }^{2}$ Ibidem. p. 8 .

${ }^{3}$ LISSOVSKY, Maurício; MORAES DE SÁ, Paulo Sérgio: Colunas da Educação. A construção do Ministério da Educação e Saúde. Rio de Janeiro: MINC/IPHAN, Fundação Getúlio Vargas/CPDOC, 1996.p. 13. (Traducción del autor)
} 
proyecto elegido fue el del arquitecto Archimedes Memória, entonces director de la Escuela Nacional de Bellas Artes. Se pagó el premio al arquitecto, pero el Ministro Gustavo Capanema decide no construir el proyecto ganador y, por medio de Carlos Drummond de Andrade, invita a Lucio Costa para preparar una propuesta para el MES el día 25 de marzo de 1936. Lucio Costa forma un equipo constituido por Oscar Niemeyer, Affonso Eduardo Reidy, Carlos León, Jorge Moreira, Ernani Vasconcelos y por él mismo. Al mismo tiempo, por sugerencia de Lucio Costa, el equipo se puso en contacto con Le Corbusier para que visitase Brasil para dar su opinión sobre el proyecto en curso para el MES, sobre los planes de la Cidade Universitária do Brasil y para que promoviese un ciclo de conferencias sobre arquitectura moderna.

En mayo, el equipo de arquitectos presentó una memoria descriptiva donde se percibe la influencia de los principios de la nueva arquitectura de Le Corbusier. Proyectado con una estructura independiente del cerramiento que dotaba a las fachadas de libertad, fue diseñado un volumen principal de 7 plantas conectado a dos alas de 5 plantas, todos apoyados sobre pilotis y un bloque anejo que albergaba una sala de conferencias.

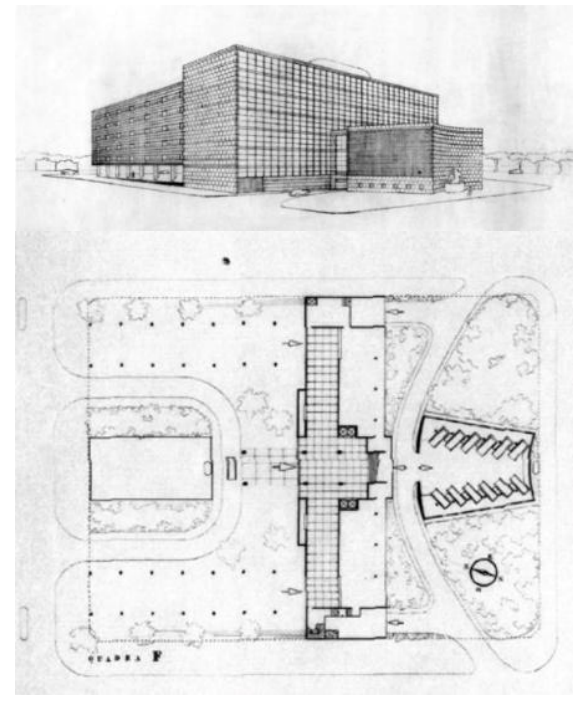

1.Primera versión del Ministerio de Educación y Salud. Proyecto del equipo de arquitectos brasileños.

En una carta a Gustavo Capanema, Le Corbusier mostraba su excitación por el viaje a Río de Janeiro: "Creo que sería una gran alegría para un arquitecto como yo encontrar en este magnífico paisaje la oportunidad de construir una obra de madurez capaz de revelar las posibilidades de la arquitectura moderna" ${ }^{4}$. Quería vincular su visita al desarrollo de alguna obra arquitectónica. Dijo:

"Estoy en una edad que ya no me permite desplazarme tan lejos para simplemente dar conferencias a estudiantes. Es indispensable para mí el poder crear obras arquitectónicas, ya sean pequeñas o grandes, aunque significativas. Expongo el problema de manera muy nítida, dejando claro que no puedo dar cursos de arquitectura y urbanismo en Río a menos que sea asegurada formalmente mi participación en una obra de arquitectura o urbanismo, en colaboración con los arquitectos brasileños ${ }^{\prime 5}$.

\footnotetext{
${ }^{4}$ LE CORBUSIER apud LISSOVSKY, Maurício; MORAES DE SÁ, Paulo Sérgio: Colunas da Educação. A construção do Ministério da Educação e Saúde. Rio de Janeiro: MINC/IPHAN, Fundação Getúlio Vargas/CPDOC, 1996.p. 59. (Traducción del autor)

${ }^{5}$ Idem.
} 
Después de hacerse oficial la llegada de Le Corbusier, Lucio Costa y él intercambiaron algunas cartas. Los temas fueron la arquitectura moderna, sus obstáculos en Brasil y el envío de las propuestas del equipo brasileño a Le Corbusier. Costa dijo que la mayoría de la gente no entiende completamente la arquitectura moderna y apenas oyeron hablar de la "máquina de habitar", y que había mucho por conocer aún. Cuenta que a él mismo le llevó algún tiempo entender las ideas de Le Corbusier, y que cuando éste llegó a Brasil por primera vez en 1929, tampoco lo entendió. En una carta del 26 de junio de 1936, Lucio Costa escribe:

"Durante su visita a Río de Janeiro en 1929, asistí a su conferencia: llegué a mitad del acto, la sala estaba llena - cinco minutos más tarde me fui escandalizado, convencido sinceramente de que había visto a un 'charlatán'. Entiendo muy bien, por tanto, el malentendido que persiste, ya que la mayoría aún está en esa etapa" ${ }^{6}$.

No obstante, en la misma carta, aclara un poco más tarde, que, cuando ya es director de la Escuela de Bellas Artes de Río de Janeiro,

"Se produjo un cambio profundo - el 'tradicionalista' que solía ser, en el mal sentido de la palabra, había sido capaz de superar gradualmente la repugnancia que sus libros me producían y de repente, como una revelación, toda la conmovedora belleza de su espíritu me impresionó. En 'estado de gracia' y con la fe inquebrantable de los recién convertidos, jtraté de 'salvar' a los jóvenes de la Escuela!"7.

En el mismo texto, Lucio Costa explicó la realización del concurso para la construcción del MES y el proyecto ganador y no construido, así como toda la red de contactos que se establecieron, resultando finalmente en la idea de un proyecto de arquitectos brasileños con el asesoramiento de Le Corbusier. En virtud de eso le hizo una cuidadosa petición:

"Apenas una sola cosa más. Una de sus tareas, junto al ministro, será la de dar su opinión sobre el proyecto del cual envío fotografías. Si le desagrada, díganoslo sin contemplaciones, pero por favor, no le diga de una manera seca al Sr. Capanema: 'Es feo... ellos no me entendieron' - porque entonces estaríamos perdidos sin remisión, ya que los 'otros' ya lo condenaron y por eso solicitamos su opinión" ${ }^{\prime 8}$.

La situación era delicada. La evaluación de Le Corbusier tenía que ser favorable, aunque fuese sólo en parte. Fue necesario un proceso de aceptación de la modernidad. Los esfuerzos de Gustavo Capanema, Carlos Drummond de Andrade, Lucio Costa y de todos los otros arquitectos habrían sido en vano si Le Corbusier no hubiese reconocido su doctrina en el edificio, o simplemente rechazase el proyecto. No servirían de nada todos los discursos en favor del modernismo que se habían hecho hasta aquel momento en Brasil si Le Corbusier no avalase los intentos de los arquitectos.

\footnotetext{
${ }^{6}$ LUCIO COSTA apud LISSOVSKY, Maurício; MORAES DE SÁ, Paulo Sérgio: Colunas da Educação. A construção do Ministério da Educação e Saúde. Rio de Janeiro: MINC/IPHAN, Fundação Getúlio Vargas/CPDOC, 1996. p. 93. (Traducción del autor)

${ }^{7}$ Idem.

${ }^{8}$ LUCIO COSTA apud LISSOVSKY, Maurício; MORAES DE SÁ, Paulo Sérgio: Colunas da Educação. A construção do Ministério da Educação e Saúde. Rio de Janeiro: MINC/IPHAN, Fundação Getúlio Vargas/CPDOC, 1996. p. 93. (Traducción del autor)
} 
Le Corbusier llegó a Río de Janeiro el 12 de julio. Desde el 31 de julio hasta el 14 de agosto se habían programado seis conferencias sobre arquitectura moderna ${ }^{9}$. Antes de llegar a Brasil, Le Corbusier ya había recibido el proyecto desarrollado por el equipo brasileño y lo había considerado como prometedor. En su informe al Ministro menciona la aplicación de las teorías modernas de la arquitectura que defendió, elogiando la buena orientación, la solución de la estructura del edificio y el esquema de iluminación. Afirma que "este proyecto se puede clasificar por su valor arquitectónico entre los mejores de la historia que se hayan hecho hasta hoy sin importar en cual país ${ }^{\prime 10}$ y admitiendo algunas reservas desde el punto de vista plástico en cuanto a la simetría, sostenía que el terreno contenía algunas características que podrían haber limitado las soluciones. Por lo tanto - en relación con el lugar elegido en la Esplanada do Castelo - sostuvo que "sería desolador soportar los costes de un edificio tan bien diseñado"11 en un terreno con una mala localización. Afirmó que "el principio y la esencia de una obra arquitectónica reside en su ubicación. La ubicación es equivalente a más de la mitad del diseño arquitectónico y es claramente decisiva"12, proponiendo "no corregir el proyecto, que es excelente, sino a cambiar la localización, que es inadecuada"13. En el mismo informe, Le Corbusier refiere que puso en duda la elección del terreno, obteniendo la respuesta de que "toda la libertad era aún posible"114. Por ello, estaba dispuesto a colaborar en la búsqueda de otro terreno, decidiéndose, más tarde, por una zona junto al mar.

Para el nuevo terreno, situado cerca del mar y próximo al aeropuerto, presenta una propuesta que afirma que no es nueva, sino una reelaboración del diseño de los arquitectos brasileños. Le Corbusier escribe:

"Insisto en que este no es un nuevo palacio, sino el mismo, cuyas alas se abren. En consecuencia, el nuevo palacio tiene las mismas secciones constructivas, los mismos locales y, en principio, la misma disposición. En compensación, los servicios de la sala de conferencias y del vestíbulo mejoraron de manera significativa"15.

Este proyecto se muestra en Euvre complète 1934-38. La propuesta es de un edificio en bloque horizontal, más bajo que la propuesta de los brasileños y con vistas privilegiadas hacia la Bahía de Guanabara.

\footnotetext{
${ }^{9}$ LISSOVSKY, Maurício; MORAES DE SÁ, Paulo Sérgio: Colunas da Educação. A construção do Ministério da Educação e Saúde. Rio de Janeiro: MINC/IPHAN, Fundação Getúlio Vargas/CPDOC, 1996.

${ }^{10}$ LE CORBUSIER apud LISSOVSKY, Maurício; MORAES DE SÁ, Paulo Sérgio: Colunas da Educação. A construção do Ministério da Educação e Saúde. Rio de Janeiro: MINC/IPHAN, Fundação Getúlio Vargas/CPDOC, 1996. p. 109. (Traducción del autor)

${ }^{11}$ Ibidem, p. 110.

${ }^{12}$ Idem.

${ }^{13}$ Idem

${ }^{14}$ Ibidem. p. 109.

${ }^{15}$ LE CORBUSIER apud LISSOVSKY, Maurício; MORAES DE SÁ, Paulo Sérgio: Colunas da Educação. A construção do Ministério da Educação e Saúde. Rio de Janeiro: MINC/IPHAN, Fundação Getúlio Vargas/CPDOC, 1996. p. 112. (Traducción del autor)
} 


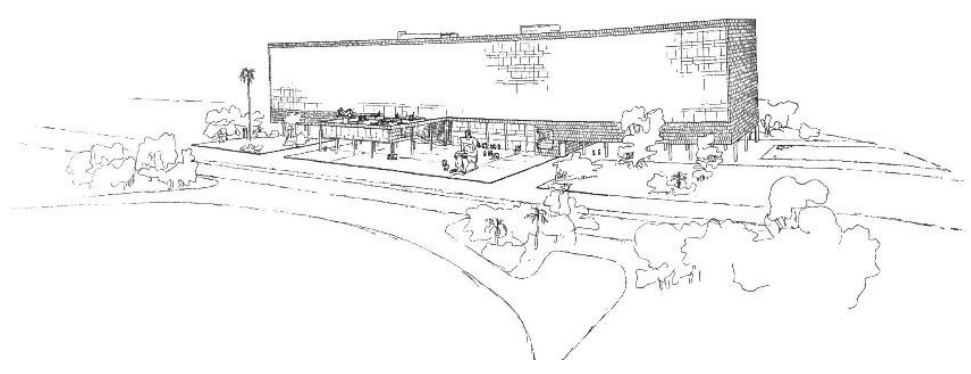

2. Propuesta de Le Corbusier para el nuevo terreno elegido por él. Publicado en Euvre complète 1934-38.

A lo largo de su estancia en Río de Janeiro, Le Corbusier se dedica a concretar el cambio de terreno, destacando las posibilidades arquitectónicas que se perderían si fuese ubicado en el terreno de la Esplanada do Castelo. Si esto ocurriera, Le Corbusier temía que se convirtiese en "un conjunto arquitectónico de tal naturaleza que de ninguna manera, a pesar de toda la perfección del edificio, fuese posible conseguir una impresión de nobleza y grandeza"16. No obstante, por diversas razones administrativas, no fue posible modificar el terreno, siendo uno de los problemas principales su proximidad al aeropuerto, donde la altura requerida para los edificios era demasiado baja. Por ello, volvieron al terreno de la Esplanada do Castelo, para el cual el proyecto diseñado por Le Corbusier no era factible. Al mismo tiempo, la permanencia de Le Corbusier en Brasil había llegado a su fin. Gustavo Capanema consiguió que Le Corbusier dejase algunos dibujos, hechos a última hora, para el terreno original. El arquitecto mantuvo un volumen principal horizontal en uno de los lados del terreno, conformando una plaza de acceso con el bloque de servicios perpendicular al volumen horizontal.

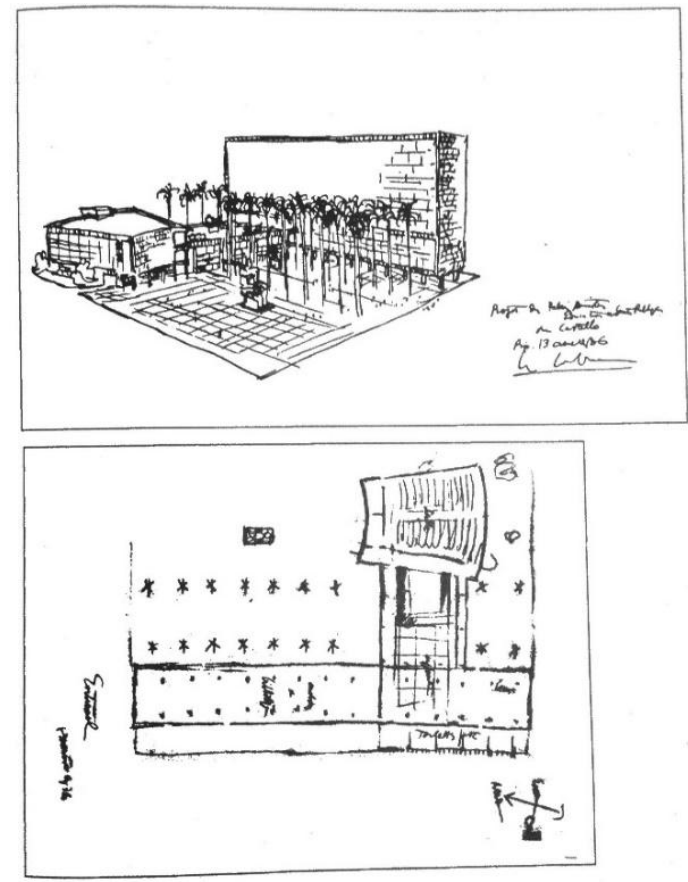

3. Propuesta de Le Corbusier para el terreno original.

${ }^{16}$ Ibidem, p. 19. 
Aun así, el proyecto brasileño siguió obteniendo opiniones de diversos profesionales e incorporando las sugerencias de Le Corbusier, con el fin de llegar a un proyecto definitivo. Los brasileños no querían construir su proyecto inicial, pero no estaban satisfechos con la propuesta dada por Le Corbusier. Fue necesario mucho trabajo para llegar a un acuerdo final basado en el diseño dejado por el maestro, pero cambiando la relación entre los tres volúmenes propuestos. Lucio Costa escribe el 3 de julio 1937 a Le Corbusier:

"Reconocida la imposibilidad de construir en el magnífico terreno que elegiste - porque tendría que ser mucho más bajo y sin la posibilidad de desarrollarlo inmediatamente debido a su proximidad al aeropuerto; y confirmado, por otro lado, que la 'momia'[17] estaba bien muerta - hicimos un nuevo diseño, inspirado directamente en sus croquis" ${ }^{\prime 18}$.

La respuesta de Le Corbusier es recibida el mismo mes:

"Su edificio del Ministerio de Educación y Salud me parece excelente. Incluso me atrevería a decir: animado por un espíritu clarividente, consciente de los objetivos: servir y emocionar. No tiene estos vacíos o barbarismos que a menudo vemos en otras obras modernas y que muestran que no se sabe lo que es la armonía. ¿Se está construyendo? ¿Sí? Entonces mucho mejor, y estoy seguro de que será hermoso. [...] Mi enhorabuena, mi 'OK' (como usted quería) ${ }^{\prime \prime 19}$.

El 30 de diciembre, Le Corbusier escribió a Gustavo Capanema: "Recibí hace unas semanas los planos y las fotografías del Ministerio, actualmente en construcción. Sigo detestando el terreno en el que lo construyen, pero creo que el espíritu innovador que anima a este edificio, con el paso del tiempo, lo convertirá en una cosa excelente $^{\prime 20}$.

El proyecto estuvo marcado por el racionalismo y funcionalismo predicado por Le Corbusier, y siguió los cinco principios: los pilotis, la planta libre, el jardín-terraza, la fachada libre y la piel de vidrio. Se le dio una gran importancia a la integración con obras de arte, integrando revestimientos de azulejos, frescos y esculturas. El Ministerio de Educación y Salud no estuvo exento de críticas, pero al mismo tiempo se divulgó en el extranjero con gran interés por varias publicaciones como el New York Times en 1943, y L'Architecture d'Aujourd'hui en $1947^{21}$. Más tarde, fue renombrado como Palácio da Cultura y fue inaugurado el 3 de octubre $1945^{22}$.

\section{Euvre complète 1934-38}

En este trabajo, publicado por Max Bill, y con textos de Le Corbusier en 1939, el Ministerio de Educación y Salud aún estaba en construcción. El texto menciona la invitación al arquitecto franco-suizo realizada por el Ministro de Educación y Salud y por el Comité de arquitectos responsables por el proyecto. Muestra que Le

\footnotetext{
${ }^{17}$ Nombre dado por Le Corbusier al primer proyecto del equipo brasileño.

${ }^{18}$ LUCIO COSTA apud LISSOVSKY, Maurício; MORAES DE SÁ, Paulo Sérgio: Colunas da Educação. A construção do Ministério da Educação e Saúde. Rio de Janeiro: MINC/IPHAN, Fundação Getúlio Vargas/CPDOC, 1996. p. 137. (Traducción del autor)

${ }^{19}$ LE CORBUSIER apud SEGAWA, Hugo: Arquiteturas no Brasil: 1900-1991.São Paulo: Edusp, 2010. p.91. (Traducción del autor)

${ }^{20}$ LE CORBUSIER apud LISSOVSKY, Maurício; MORAES DE SÁ, Paulo Sérgio. Op.cit.. p. 140. (Traducción del autor)

${ }^{21}$ CAVAlCANTI, Lauro (org.): Quando o Brasil era Moderno - Guia de Arquitetura 1928-1960. Rio de Janeiro: Aeroplano, 2001, p. 373.

${ }^{22}$ LISSOVSKY, Maurício; MORAES DE SÁ, Paulo Sérgio. Op.cit. p. 12.
} 
Corbusier se mostró inflexible en la sustitución del terreno, eligiendo otro para el cual elaboró planos con los arquitectos del Comité.

El principal proyecto está diseñado para el terreno cerca del mar elegido por Le Corbusier. Se publican una perspectiva general del edificio (ver Figura 2), un diseño del paisaje donde se implantaría, un esquema de circulaciones y varias imágenes de cómo sería el interior del edificio y su integración con el exterior (ver figura 4).

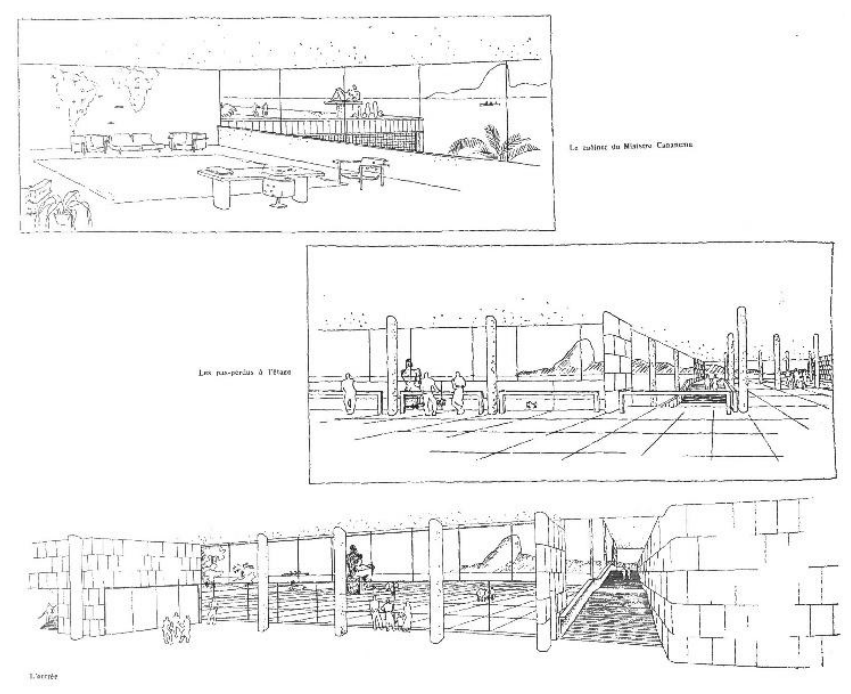

4. Propuesta de Le Corbusier para el nuevo terreno elegido por él. Publicado en Euvre complète 1934-38.

El texto continúa con la revelación de que no fue posible el cambio de terreno ${ }^{23}$, y se tuvo que volver al terreno original. Así que, en la víspera de su partida, Le Corbusier tuvo que ofrecer una propuesta al Ministro Capanema $^{24}$, pero estos diseños no aparecen en el libro, son los que se muestran anteriormente (Figura 3).

Lucio Costa resume los hechos, diciendo que Le Corbusier

"Hizo, así, varios intentos de adaptar el diseño al terreno de la Esplanada do Castelo, pero las variantes propuestas eran insatisfactorias. Cuando partió, nos quedamos con la tarea de elaborar el nuevo proyecto, basado en su proyecto inicial para la bahía, manteniendo lo esencial, pero modificando la implantación, la dirección (norte-sur en lugar de este-oeste), y aumentando la altura.

Cuando terminamos el proyecto, le enviamos copias y la foto de la maqueta, a lo que respondió enalteciendo el diseño. Lo que creó la confusión fue el trazo que Le Corbusier hizo después, calcado en la fotografía de la maqueta, divulgado en una publicación de Zurich" ${ }^{\prime 25}$.

\footnotetext{
${ }^{23}$ LE CORBUSIER \& JEANNERET, Pierre. CEuvre complète. Vol 3. 1934-1938. Zürich: Les Éditions d'Architecture, 1995. (Publicado originalmente en 1938) p. 78.

24 “Avant son départ, Le Corbusier dut fournir au ministre une proposition d'adaptation de ser plans sur le terrain antérieurement choisi. On voit sur la gauche du croquis de droite l’usage habituel des terrains en question, à Rio: façades sur rues étroites et cours intérieures. Le projet actuellement en exécution constitue une grande novation urbanistique; il permettrait de tirer un parti admissible des tracés fâcheux de rues et de blocs ed d'introduire à nouveau l'espace dans le site Urbain, ainsi que des moyens efficaces de circulation". LE CORBUSIER \& JEANNERET, Pierre. Euvre complète. Vol 3. 1934-1938. Zürich: Les Éditions d'Architecture, 1995. (Publicado originalmente en 1938) p. 78.
} 
Las tres últimas imágenes muestran el diseño final para el Ministerio de Educación y Salud y causan una cierta confusión. En la primera gran perspectiva (Figura 5) la leyenda sugiere que esta sería la propuesta hecha en el último momento ${ }^{26}$ por Le Corbusier, y, sin embargo, es el esbozo del proyecto final que se construyó después de meses de trabajo y con las modificaciones hechas por los arquitectos brasileños, sobre la base de la propuesta dejada por Le Corbusier.

Según Bruand hubo una gran polémica: "En lugar de ser el proyecto original de Le Corbusier el que había servido de base para el posterior desarrollo del proyecto construido, en realidad era un dibujo hecho, a posteriori, en función de los planos definitivos, que Lucio Costa y el equipo enviaron a Le Corbusier en 1937"27.

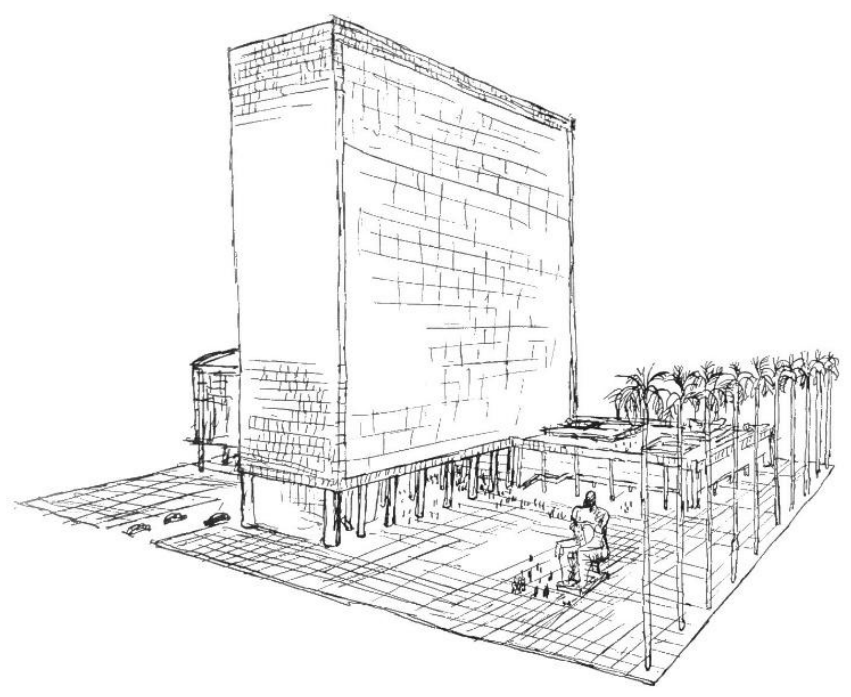

5. Propuesta final del equipo de arquitectos brasileños, basado en las indicaciones y dibujos dejados por Le Corbusier. Publicado en Euvre complète 1934-38.

En Euvre complète 1934-38, el texto concluye indicando que el proyecto está en ejecución y será una gran innovación urbana, mientras muestra, en uno de los dibujos, la gran diferencia entre la forma tradicional de ocupar una manzana urbana en contraste con la implantación moderna del proyecto propuesto.

\footnotetext{
25 “ “Ele nos deixou um presente...” Entrevista com Lucio Costa”. Arquitetura e Urbanismo. São Paulo: outubro e novembro de 1989. p. 25. Disponível em http://www.jobim.org/lucio/bitstream/handle/2010.3/4103/VIII\%20A\%200204143\%20L.pdf?sequence=2. Acesso em 07 jun. 2015. (Traducción del autor)

26 "Adaptation sur le terrain adopté en dernière heure des aménagementes de projet de la page 78." LE CORBUSIER \& JEANNERET, Pierre. Euvre complète. Vol 3. 1934-1938. Zürich: Les Éditions d'Architecture, 1995. (Publicado originalmente en 1938) p. 81.

${ }^{27}$ BRUAND, Yves: Arquitetura contemporânea no Brasil. São Paulo: Perspectiva, 1981. p.85. (Traducción del autor)
} 


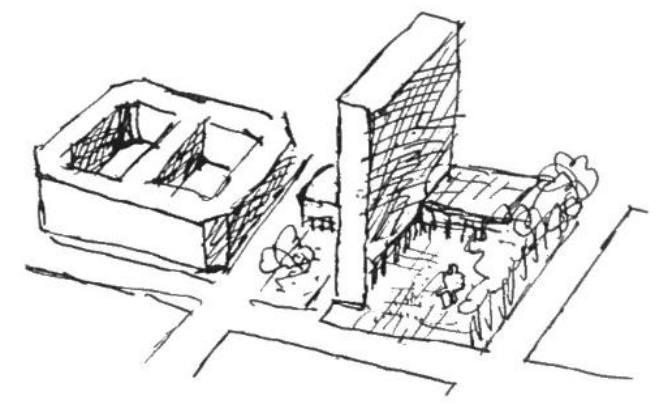

6. Ministerio de Educación y Salud. Publicado en Euvre complète 1934-38.

\section{Brazil Builds - Architecture New and Old: 1652 - 1942}

La producción arquitectónica en Brasil durante las primeras décadas del siglo XX fue significativa, y esto llamó la atención del Museo de Arte Moderno (MoMA) de Nueva York, que decidió realizar una exposición, seguida de un libro llamado Brazil Builds: Architecture New and Old: 1652-1942. Aunque también mostró alguna arquitectura antigua, era la arquitectura moderna y sus innovaciones las que tuvieron más éxito. Uno de los aspectos más destacados en este libro es el Ministerio de Educación y Salud, la primera gran obra del modernismo brasileño junto a obras destacadas como la sede de la ABI y el aeropuerto Santos Dumont. Brazil Builds fue el principal vehículo para la difusión de la arquitectura moderna brasileña en el exterior. El autor comenta sobre la obra en cuestión:

"En 1936, Le Corbusier fue invitado a ir a Río por un grupo de arquitectos encargados de la construcción del Ministerio de Educación y Salud. En esta obra se refleja su influencia de una manera muy acentuada, no obstante, lo más importante es que en ella se manifiestan libremente la imaginación del diseño y la reprobación del antiguo camino oficial. Mientras que el clasicismo de los edificios federales en Washington, lo arqueológico de la Real Academia de Londres y el clásico nazi en Múnich dominan triunfantemente, Brasil tuvo el coraje de romper con la rutina y tomar un nuevo rumbo dando como resultado el que Río de Janeiro poseyese los más bellos edificios públicos del continente Americano ${ }^{\prime 28}$.

Philip Goodwin escribió que el gran aporte de la arquitectura brasileña fueron los sistemas de control solar y de calor en los edificios a través de la utilización del brise-soleil:

"Ya en 1933, Le Corbusier recomienda el uso del brise-soleil móvil, externos, como lo eran en su proyecto no construido en Barcelona, pero fue en Brasil donde por primera vez esta teoría se pone en práctica. Tal y como los arquitectos de Brasil los han desarrollado, estos parasoles son a veces horizontales, a veces móviles, o fijos. Quebra-sol es el nombre que se les da, pero el término francés brise-soleil es más comúnmente utilizado"29.

\footnotetext{
${ }^{28}$ GOODWIN, Philip: Brazil Builds - Architecture New and Old 1652 - 1942. New York: Museum of Modern Art, MoMa, 1943. p. 91. (Traducción del autor)

${ }^{29}$ Ibidem, p. 85.
} 
Explicó que el lado sur no tenía ninguna protección, ya que está menos expuesto, mientras que el lado norte estaba protegido por el sistema de persianas horizontales móviles de los cuales había diagramas ilustrativos (Figura 6). También hay dibujos de las distintas disposiciones de los volúmenes ensayadas sobre el terreno hasta que se encontró la solución definitiva. El libro muestra nueve imágenes del edificio, dos de ellas ocupan la página entera y muestran ambos lados del edificio (Figura 7 y 8), cuatro detalles más aproximados, un detalle de la pared de azulejos de Portinari y dos fotografías de los parasoles.

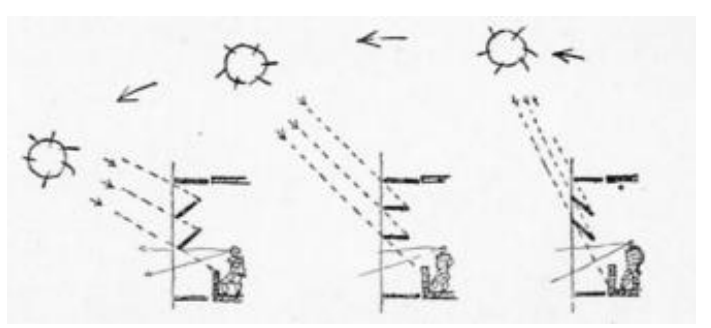

7. El funcionamiento del sistema de brise-soleil del Ministerio de Educación y Salud. Publicado en Brazil Builds.

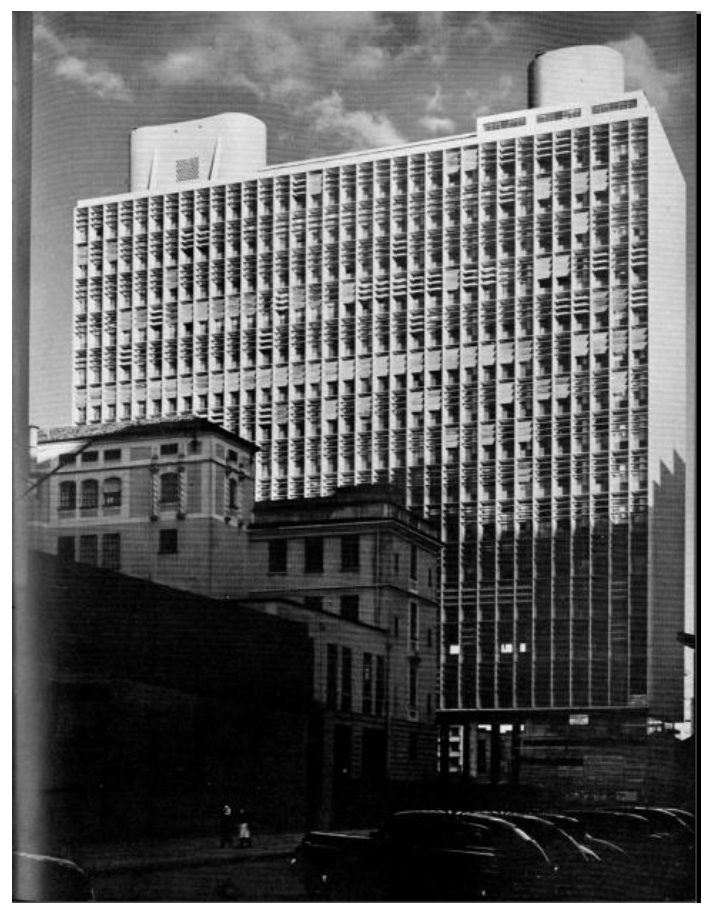

8. Ministerio de Educación y Salud. Publicado en Brazil Builds. 


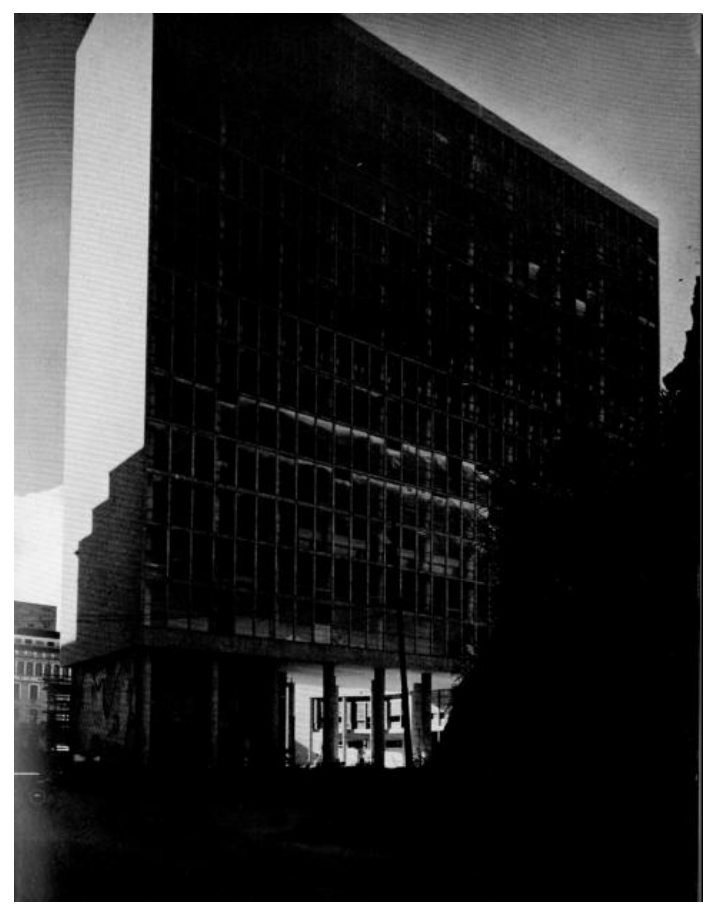

9. Ministerio de Educación y Salud. Publicado en Brazil Builds.

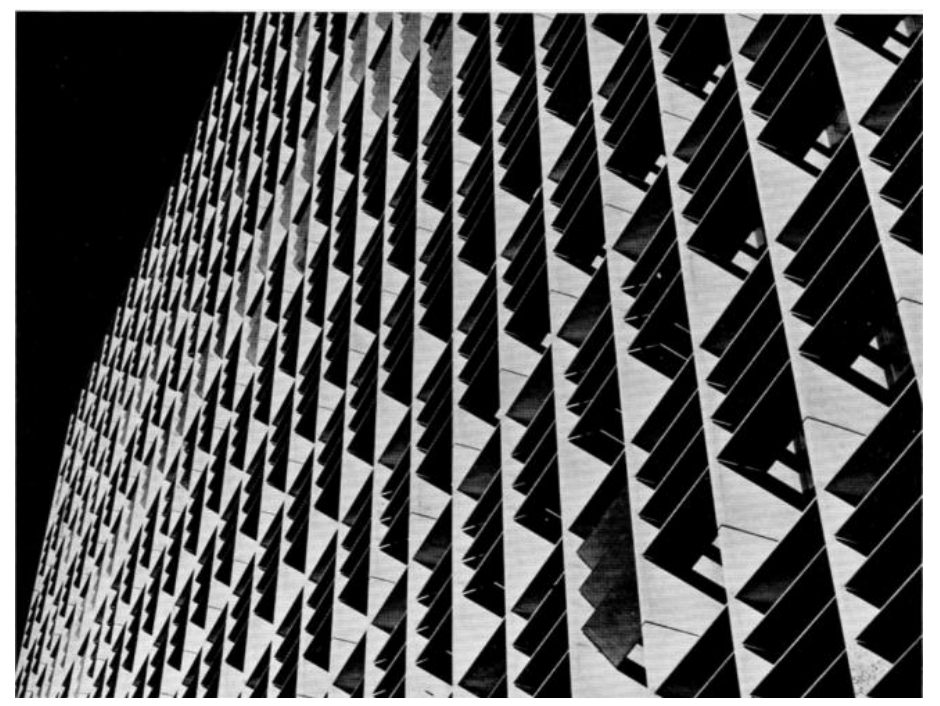

10. Brise-soleil del Ministerio de Educación y Salud. Publicado en Brazil Builds.

Goodwin informó de que el Ministerio de Educación y Salud se localizaba en la Avenida Graça Aranha, en la ciudad de Río de Janeiro. Los responsables fueron los arquitectos Lucio Costa, Oscar Niemeyer, Afonso Reidy, Carlos León, Jorge Moreira y Ernani Vasconcelos; así como el arquitecto consultor Le Corbusier. Se comunicó que el trabajo se había iniciado en 1937, aunque todavía estaba en proceso de construcción en el otoño de 1942. El arquitecto escribió: "Aquí no hay tan sólo belleza superficial. Cada detalle original es consecuencia de un estudio atento y cuidadoso de los más complicados problemas de la construcción moderna"30 y destacó las

\footnotetext{
${ }^{30}$ GOODWIN, Philip: Brazil Builds - Architecture New and Old 1652 - 1942. New York: Museum of Modern Art, MoMa, 1943. p. 106. (Traducción del autor)
} 
innovaciones de la construcción: "La estructura interna de hormigón permitió que las fachadas norte y sur fuesen completamente revestidas con vidrio, sin interrupción por las piezas de soporte. Las paredes laterales estrechas de los lados este y oeste, así como las columnas que sostienen el bloque principal, están revestidas con granito autóctono rosáceo-gris" ${ }^{\prime 31}$ El volumen principal fue dedicado a oficinas. El catálogo mencionó que en su terraza una 'estructura de líneas curvas' fue destinada a la maquinaria de los ascensores y depósitos de agua. Otro volumen también forma parte del edificio:

"Bajo el edificio principal, en ángulo recto con él, se encuentra un bloque bajo donde están localizados el auditorio y las salas de exposición. Las paredes son de azulejos blancos y azules, especialmente diseñados para el edificio. En la cubierta existe una terraza-jardín, para uso del Ministerio. Otros azulejos forman un gran mural sobre la base de la pared oeste del edificio principal ${ }^{\prime \prime 32}$.
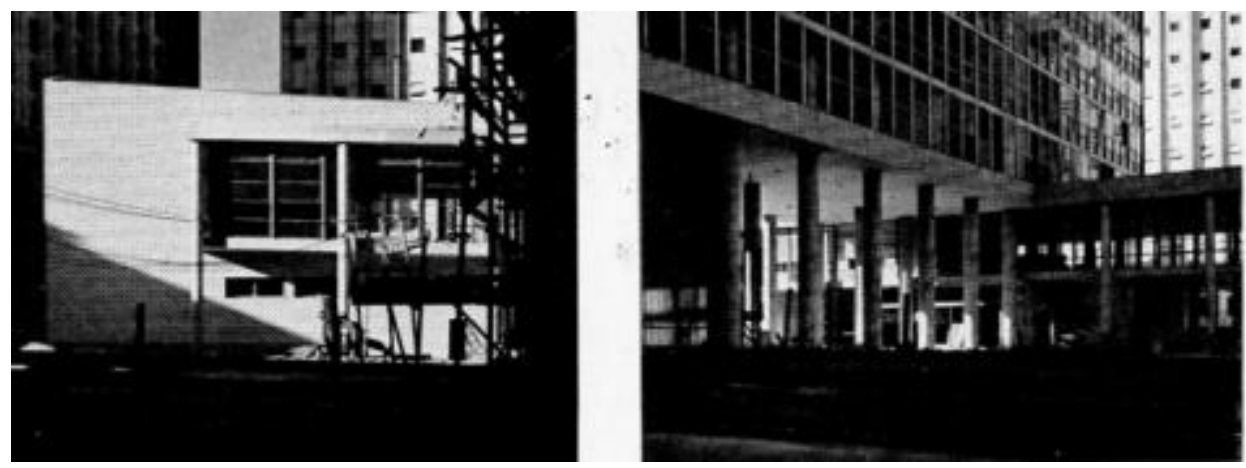

11. Vistas del Ministerio de Educación y Salud. Publicada en Brazil Builds.

Una parte del edificio ya tenía un mural diseñado por Cândido Portinari. También se muestran las plantas bajas, el segundo, tercero, cuarto y el decimoquinto piso.

\footnotetext{
${ }^{31}$ Idem.

${ }^{32}$ Ibidem. p. 108.
} 


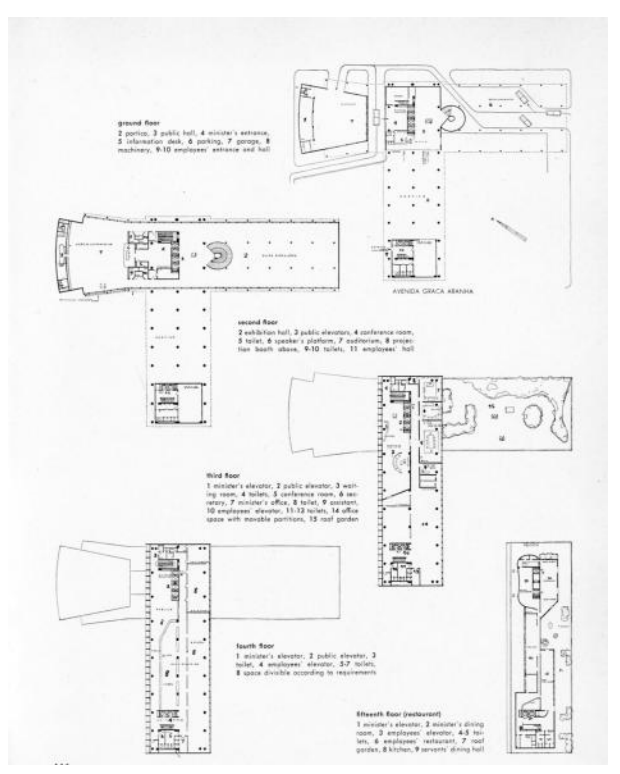

12. Plantas bajas del Ministerio de Educación y Salud. Publicado en Brazil Builds.

\section{Euvre complète 1938-46.}

En Euvre complète 1938-46 se incluyen una foto y un croquis con la descripción emocionante del paisaje de Río de Janeiro y la posibilidad de obtener hermosos encuadres a través de la arquitectura.

13. Croquis de Rio de Janeiro Euvre complète 1938-46

Aparecen los nombres de los arquitectos brasileños y de Le Corbusier como arquitecto consultor, invitado por Gustavo Capanema para revisar los planos para el Ministerio de Educación y Salud y hace una referencia a Euvre complète 1934-38, que había publicado parte del material. Se refería brevemente la cuestión del cambio de terreno que no llegó a materializarse, y se destacó el hecho de que el edificio, en un terreno estrecho, tuviese una implantación contraria a los usos tradicionales y liberase el suelo.

El texto refiere un importante libro publicado en medio de la guerra: Brazil Builds, y cita varios pasajes:

"Francia siempre tuvo una gran influencia en la cultura brasileña, tanto en el campo de la educación, como en el campo de la literatura, así como en la ciencia y las artes. Las ideas revolucionarias del gran arquitecto franco-suizo Le Corbusier fueron recibidas con simpatía especial por los jóvenes arquitectos brasileños, y sus enseñanzas se pusieron en práctica con especial brillo en el Ministerio de Educación y en otras obras en Belo Horizonte" 33.

\footnotetext{
${ }^{33}$ GOODWIN, Philip: Brazil Builds - Architecture New and Old 1652 - 1942. New York: Museum of Modern Art, MoMa,
} 1943. p. 81. (Traducción del autor) 
El desafío era el de encontrar soluciones para la incidencia del sol en los edificios

"Su gran aportación a la nueva arquitectura son las innovaciones para evitar el calor y los reflejos luminosos en las superficies de vidrio, a través de brise-soleils externos especiales. En América del Norte es una cosa poco conocida. Teniendo que soportar el sol de las tardes de verano, los grandes edificios, en general, son como un horno, a causa de la insuficiente protección de sus ventanas de hojas semi-cerradas. Las oficinas modestas, entonces, tienen que elegir entre una de dos alternativas posibles: o bien asarse, o bien protegerse ligeramente a través de toldos o persianas; una protección débil porque no funcionan contra los reflejos del sol en los vidrios. Y es curioso ver cómo los brasileños lidiaron con un problema muy importante cuyo estudio fue el que originó nuestro viaje ${ }^{\prime 34}$.

También se refiere al hecho de que Le Corbusier ya había recomendado el uso de los brise-soleils en Barcelona (como expliqué anteriormente), pero Brasil fue el primero en ponerlo en práctica. Menciona otras contribuciones de Le Corbusier al edificio, como la recomendación de usar el granito existente en Río de Janeiro, y no encargar piedra de Borgoña, como se hacía hasta entonces. Y sugirió que se utilizasen cerámicas portuguesas, vinculadas a los orígenes brasileños, para crear un contraste con el granito y el vidrio ${ }^{35}$. Repite dibujos que se publicaron en Euvre complète 1934-38: La primera perspectiva aparece como: 1936 - $1^{\circ}$ proyecto - Le Corbusier (Figura 2), la visión general del edificio con el subtítulo: 1936-1937 Segundo proyecto de Le Corbusier, adaptado para la ejecución en un terreno tradicional de Río (Figura 5), utiliza la comparación entre la implantación tradicional en la manzana y la implantación moderna del Ministerio (Figura 6), con la recomendación de que se ignoren los edificios vecinos, pues son fruto de una mala planificación urbana.

Las otras imágenes son fotografías y plantas bajas del edificio, probablemente ya finalizado.

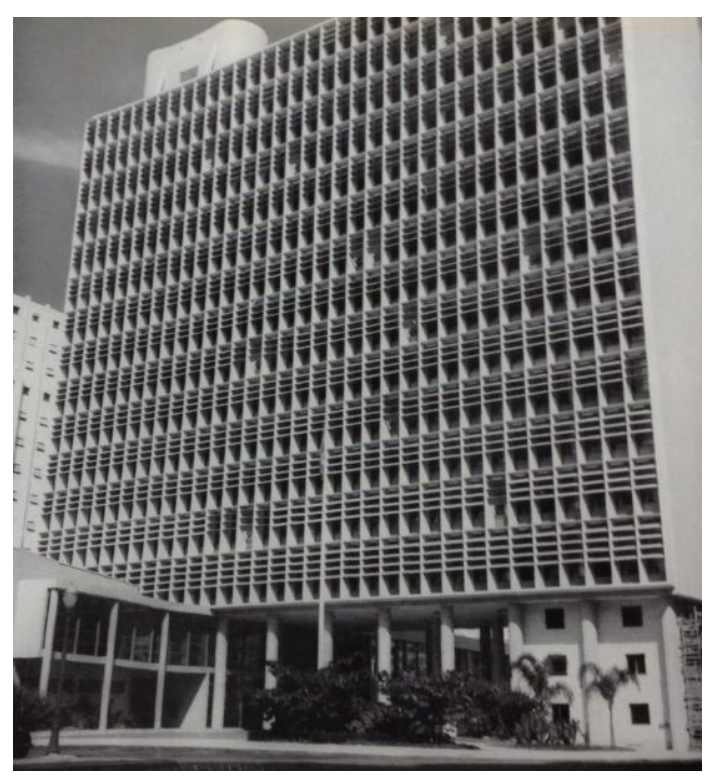

14. Ministerio de Educación y Salud. Publicado en Euvre complète 1938-46

\footnotetext{
${ }^{34}$ GOODWIN, Philip: Brazil Builds - Architecture New and Old 1652 - 1942. New York: Museum of Modern Art, MoMa, 1943. p. 85. (Traducción del autor)

${ }^{35}$ LE CORBUSIER \& JEANNERET, Pierre. Cuvre complète. Vol 4. 1938-1946. Zürich: Les Éditions d'Architecture, 1995. (Publicado originalmente en 1946).
} 


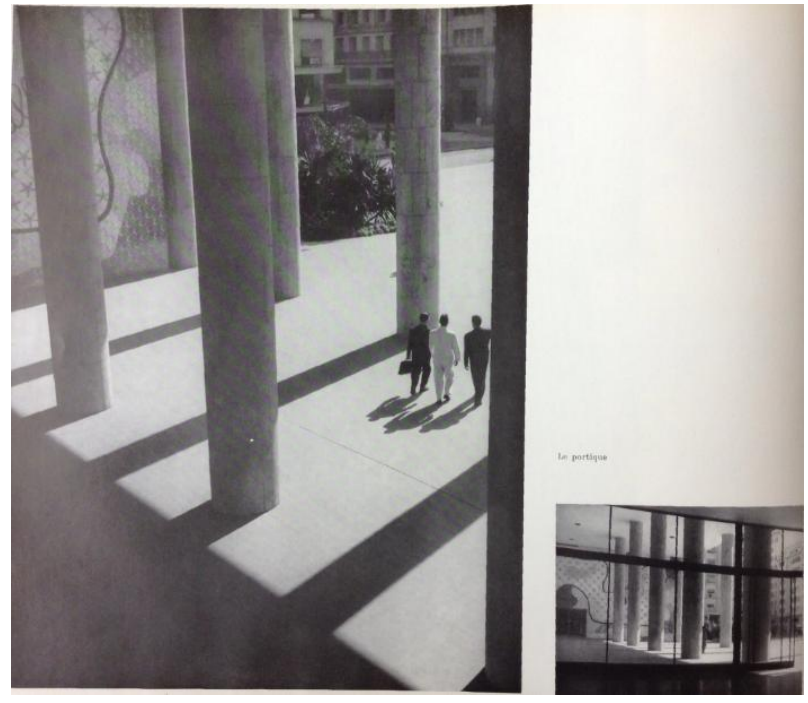

15. Ministerio de Educación y Salud. Publicado en Euvre complète 1938-46

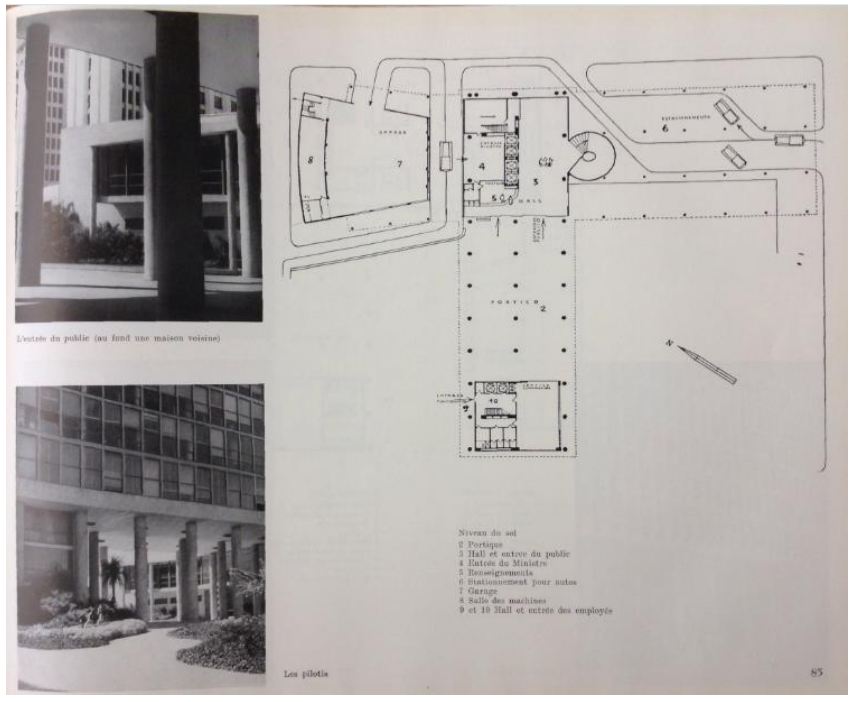

16. Ministerio de Educación y Salud. Publicado en Euvre complète 1938-46 


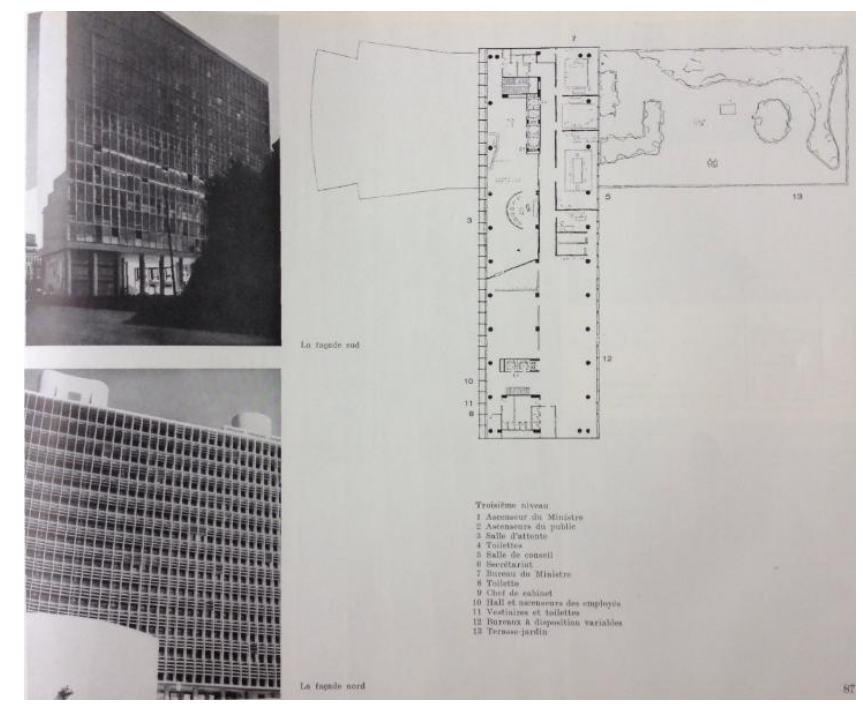

16. Ministerio de Educación y Salud. Publicado en Euvre complète 1938-46

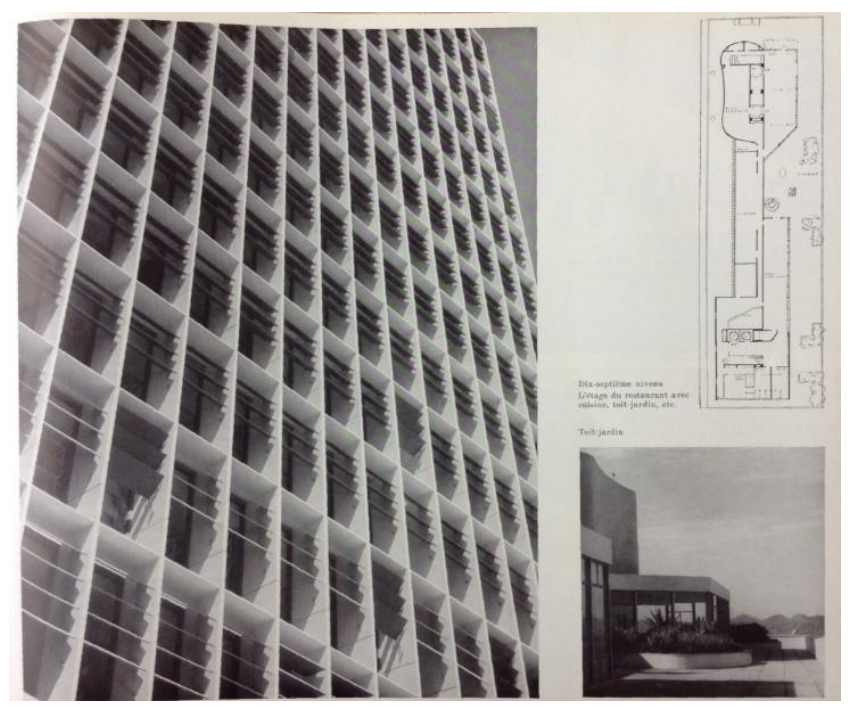

17. Ministerio de Educación y Salud. Publicado en Euvre complète 1938-46

\section{Consideraciones finales}

Durante todo el proceso se nota un gran compromiso de Le Corbusier con el terreno que desea cambiar. El trabajo propuesto para el terreno elegido cerca del mar fue detallado, con diseños de paisaje, con esquemas de circulación y croquis de perspectivas internas. A través del material mostrado en estos libros podemos ver hasta qué punto los trabajos avanzaron, antes de que tuviera que ser cancelado por la imposibilidad de cambiar de terreno. Durante el período en el que Le Corbusier estuvo en Brasil, los arquitectos y él mismo se dedicaron a este proyecto creyendo que sería construido. Por tanto, debe haber sido un shock cuando tuvieron conocimiento de la imposibilidad de construir en el terreno idealizado. Le Corbusier pasó toda su estancia proyectando el edificio para el terreno que le agradaba. Y en la víspera de su partida le presentaron el terreno anterior (rechazado por él) como la única alternativa. 
Con poco tiempo, Le Corbusier consigue hacer una propuesta con algunos dibujos y vuelve a Francia, probablemente frustrado. Estos dibujos fueron la base del proyecto final realizado por los arquitectos brasileños, que con los cambios de escala y de intercambio de bloques lograron llegar a un resultado definitivo que fue construido. No obstante, esta propuesta de Le Corbusier para la Esplanada do Castelo no forma parte de las publicaciones sobre el edificio.

En Euvre complète 1934-38, aparecen los diseños para el primer proyecto en el terreno cerca del mar, y luego pasan al diseño final, con perspectivas y maqueta del proyecto desarrollado por los brasileños basado en la propuesta dejada por Le Corbusier. En Brazil Builds, el Ministerio de Educación y Salud fue la gran sorpresa. Junto a otras obras, destacó con sus medidas de protección contra el sol. Las fotografías publicadas eran todavía de un edificio en construcción, pero ya se podía entrever el edificio en el que se convertiría.

En Euvre complète 1938-46 la narración comienza describiendo Río de Janeiro y las hermosas vistas que ofrece. El libro cita Euvre complète 1934-38, y especialmente Brazil Builds, que había logrado un gran éxito. Aquí se publican más fotos, detalles y planos de plantas bajas, de la obra ya inaugurada. Pero los dibujos publicados fueron de nuevo los del primer proyecto del terreno junto al mar, y como segunda propuesta, el diseño final, omitiendo la propuesta para la Esplanada do Castelo hecha por Le Corbusier en el último día. Siendo para un terreno difícil y con un tiempo muy limitado, su omisión puede significar que el arquitecto no estaba muy satisfecho con el resultado, no obstante, esta es una parte importante para la comprensión del proceso y lo esclarecería en gran medida, ya que es una etapa intermedia entre las dos soluciones.

Con el análisis de los tres libros se obtiene una visión general del proceso de diseño desde el principio del proyecto hasta el final de la construcción, es decir, se puede entender la creación de un edificio. Mientras que el primer libro muestra las primeras aspiraciones, y cuenta con planos y dibujos lo que sería el edificio, el segundo muestra la construcción en curso, detalles por terminar, y atisbos del futuro por imaginar. Y finalmente, el tercero muestra toda la historia, los diseños y las fotografías del edificio finalizado.

\section{Lista de imágenes}

1. Comas, Carlos Eduardo . Projeto arquitetônico, obra coletiva: o caso do Ministério da Educação. In: Projetar II Seminário sobre Ensino e Pesquisa em Projeto de Arquitetura, 2005, Rio de Janeiro. Anais do Projetar II. Rio de Janeiro: PROARQ UFRJ, 2005. v. 1. p. 5 y 6

2. Le corbusier \& Jeanneret, Pierre. Euvre complète. Vol 3. 1934-1938. Zürich: Les Éditions d'Architecture, 1995. (Publicado originalmente en 1938) p. 78.

3. Lissovsky, Maurício; MORAES DE SÁ, Paulo Sérgio: Colunas da Educação. A construção do Ministério da Educação e Saúde. Rio de Janeiro: MINC/IPHAN, Fundação Getúlio Vargas/CPDOC, 1996. p.115.

4. Le Corbusier \& Jeanneret, Pierre. Euvre complète. Vol 3. 1934-1938. Zürich: Les Éditions d'Architecture, 1995. (Publicado originalmente en 1938). p. 80.

5. Le Corbusier \& Jeanneret, Pierre. CEuvre complète. Vol 3. 1934-1938. Zürich: Les Éditions d'Architecture, 1995. (Publicado originalmente en 1938) p. 81.

6. Le Corbusier \& Jeanneret, Pierre. Euvre complète. Vol 3. 1934-1938. Zürich: Les Éditions d'Architecture, 1995. (Publicado originalmente en 1938) p. 81.

7. Goodwin, Philip: Brazil Builds - Architecture New and Old 1652 - 1942. New York: Museum of Modern Art, MoMa, 1943. p. 85.

8. Goodwin, Philip: Brazil Builds - Architecture New and Old 1652 - 1942. New York: Museum of Modern Art, MoMa, 1943. p. 107. 
9. Goodwin, Philip: Brazil Builds - Architecture New and Old 1652 - 1942. New York: Museum of Modern Art, MoMa, 1943. p.109.

10. Goodwin, Philip: Brazil Builds - Architecture New and Old 1652 - 1942. New York: Museum of Modern Art, MoMa, 1943. p. 84.

11. Goodwin, Philip: Brazil Builds - Architecture New and Old 1652 - 1942. New York: Museum of Modern Art, MoMa, 1943. p. 108.

12. Goodwin, Philip: Brazil Builds - Architecture New and Old 1652 - 1942. New York: Museum of Modern Art, MoMa, 1943. p. 111.

13. Le Corbusier \& Jeanneret, Pierre. CEuvre complète. Vol 4. 1938-1946. Zürich: Les Éditions d'Architecture, 1995. (Publicado originalmente en 1946). p. 80 e 81.

14. Le Corbusier \& Jeanneret, Pierre. Euvre complète. Vol 4. 1938-1946. Zürich: Les Éditions d'Architecture, 1995. (Publicado originalmente en 1946) p. 83.

15. Le Corbusier \& Jeanneret, Pierre. Euvre complète. Vol 4. 1938-1946. Zürich: Les Éditions d'Architecture, 1995. (Publicado originalmente en 1946) p. 84.

16. Le Corbusier \& Jeanneret, Pierre. Euvre complète. Vol 4. 1938-1946. Zürich: Les Éditions d'Architecture, 1995. (Publicado originalmente en 1946) p. 85.

17. Le Corbusier \& Jeanneret, Pierre. Euvre complète. Vol 4. 1938-1946. Zürich: Les Éditions d'Architecture, 1995. (Publicado originalmente en 1946) p. 86.

\section{Bibliografía}

Arquitetura e Urbanismo. São Paulo: outubro e novembro de 1989. Disponível em http://www.jobim.org/lucio/bitstream/handle/2010.3/4103/VIII\%20A\%2002-04143\%20L.pdf?sequence=2.

BRUAND, Yves: Arquitetura contemporânea no Brasil. São Paulo: Perspectiva, 1981.

CAVALCANTI, Lauro (org.): Quando o Brasil era Moderno - Guia de Arquitetura 1928-1960. Rio de Janeiro: Aeroplano, 2001.

COMAS, Carlos Eduardo. Projeto arquitetônico, obra coletiva: o caso do Ministério da Educação. In: Projetar II Seminário sobre Ensino e Pesquisa em Projeto de Arquitetura, 2005, Rio de Janeiro. Anais do Projetar II. Rio de Janeiro: PROARQ UFRJ, 2005. v. 1.

GOODWIN, Philip: Brazil Builds - Architecture New and Old 1652 - 1942. New York: Museum of Modern Art, MoMa, 1943.

LE CORBUSIER \& JEANNERET, Pierre. CEuvre complète. Vol 3. 1934-1938. Zürich: Les Éditions d'Architecture, 1995. (Publicado originalmente en 1938)

Euvre complète. Vol 4. 1938-1946. Zürich: Les Éditions d'Architecture, 1995. (Publicado originalmente en 1946)

LISSOVSKY, Maurício; MORAES DE SÁ, Paulo Sérgio: Colunas da Educação. A construção do Ministério da Educação e Saúde. Rio de Janeiro: MINC/IPHAN, Fundação Getúlio Vargas/CPDOC, 1996.

SEGAWA, Hugo: Arquiteturas no Brasil: 1900-1991.São Paulo: Edusp, 2010.

WILLIANS, Richard: Brazil - Modern Architectures in history. Londres: Reaktion Books Ld, 2009. 